\title{
Robotic adenomectomy using a laparoscopic dissector
}

\author{
Lessandro Curcio Gonçalves ${ }^{1}$, Felipe Monnerat Lott ${ }^{2}$, Rafael Rosa ${ }^{1}$ \\ ${ }^{1}$ Serviço de Urologia, Hospital Federal de Ipanema, Rio de Janeiro, RJ, Brasil; ${ }^{2}$ Departamento de Urolo- \\ gia, Instituto Nacional de Câncer (INCA), Rio de Janeiro, RJ, Brasil
}

\section{ABSTRACT}

Introduction: Only few reports are known about the use of robotic surgery for prostate benign enlargement. The robotic surgery can be improved by laparoscopic tricks. We show a video of robotic adenomectomy where a laparoscopic dissector is used to help create the plan between prostatic capsule and adenoma.

Materials and methods: A 62 years old male had severe urinary flow outlet obstruction. Medical therapy was not effective. Ultrasound detected a 92gr enlarged prostate with a large middle lobe. Robotic assisted adenomectomy was scheduled. The procedure followed this sequence: opening of Retzius space, superficial suture of the Dorsal vein complex, horizontal cistotomy. The plan was created with electrocautery and blunt dissection with the laparoscopic dissector. Haemostatic sutures were placed between prostate fossa and the posterior bladder neck and closure of the cistotomy.

Results: Whole operation time was 160 minutes, with a blood loss of 80cc. There was no perioperative or post-operative complication. Catheter was removed after 4 days. Post-operatory uroflowmetry shows a peak flow of 30ml/sec. Pathological examination is negative for tumor. After 60 days IPSS was 8.

Conclusion: Robotic prostate adenomectomy using the laparoscopic dissector is a safe and effective minimally invasive treatment for benign prostatic enlargement. It is a novel technique to find and dissect the plane between prostatic adenoma and capsule. This could be one more use of laparoscopic technology to improve surgical outcomes in robotic field.

\section{CONFLICT OF INTEREST}

None declared.

\section{ARTICLE INFO}

Available at: http://www.intbrazjurol.com.br/video-section/20170609_Goncalves_et_al Int Braz J Urol. 2018; 44 (Video \#17): 1051-1051

Submitted for publication:

November 15, 2017

Accepted after revision:

February 18, 2018

Published as Ahead of Print:

March 15, 2018
Correspondence address:

Lessandro Curcio Gonçalves, MD

Serviço de Urologia

Hospital Federal de Ipanema

R. Antônio Parreiras, 67 - Ipanema,

Rio de Janeiro - RJ, 22411-020, Brasil

Telephone: + 5521 3259-3275

E-mail: lessandrocg@ig.com.br 